Original Research Paper

\title{
Solar Tracker
}

\section{Irfan Danial Hisham ${ }^{1}$, Ammar Asyraf Ismail ${ }^{1}$, Muhammad Arief Azizi ${ }^{1}$}

${ }^{1}$ Department of Computing, Faculty of Arts, Computing and Creative Industry, Universiti Pendidikan Sultan Idris, Malaysia.

Article history

Received:

05.01.2020

Revised:

14.02.2020

Accepted:

16.03.2020

*Corresponding Author:

Irfan Danial bin Hisham

Email:

irfan.hisham09@gmail.com

This is an open access article, licensed under: $C C-B Y-S A$
Abstract: The generation of power from the reduction of fossil fuels is the biggest challenge for the next half century. The idea of converting solar energy into electrical energy using photovoltaic panels holds its place in the front row compared to other renewable sources. But the continuous change in the relative angle of the sun with reference to the earth reduces the watts delivered by solar panel. Conventional solar panel, fixed with a certain angle, limits their area of exposure from the sun due to rotation of the earth. Output of the solar cells depends on the intensity of the sun and the angle of incidence. To solve this problem, an automatic solar cell is needed, where the Solar Tracker will track the motion of the sun across the sky to ensure that the maximum amount of sunlight strikes the panels throughout the day. By using Light Dependent Resistors, it will navigate the solar panel to get the best angle of exposure of light from the sun.

Keyword: Arduino, Internet of Things, Solar Tracker. 


\section{Introduction}

The sun is a low cost source of electricity for instead of using generators, solar panel can convert direct sun rays to electricity. Conventional solar panel, fixed with a certain angle, limits their area of exposure from the sun due to rotation of the earth. Output of the solar cells depends on the intensity of the sun and the angle of incidence.

A Solar Tracker will help to reduce the usage of fossil gas and also to make the environment clean. The Solar Tracker will track the motion of the sun across the sky to ensure that the maximum amount of sunlight strikes the panels throughout the day. By using Light Dependent Resistors (LDR), it will navigate the solar panel to get the best angle of exposure of light from the sun.

\section{Literature Review}

\subsection{Internet of Things}

Internet of Thing (IoT) is a concept where an object has the ability to transfer data through a network without requiring human-to-human or human-computer interaction. IoT has evolved from the convergence of wireless technology, micro-electromechanical systems (MEMS), and the Internet [1], [2] [3] [4].

Many have predicted that IoT is "The Next Big Thing" in the world of information technology, this is because IoT offers a lot of potential that can be developed again [5] [6] [7]. An example is the implementation of the Internet of Things (IoT), for example, a refrigerator that can notify its owner via SMS or email about any food and drinks that have run out and must be stocked again.

\subsection{Servo Motor}

Servo can rotate approximately 180 degrees (90 in each direction), and works just like the standard kinds but smaller. We can use any servo code, hardware or library to control these servos. Good for beginners who want to make stuff move without building a motor controller with feedback \& gear box, especially since it will fit in small places [8]. It comes with a 3 horns (arms) and hardware.

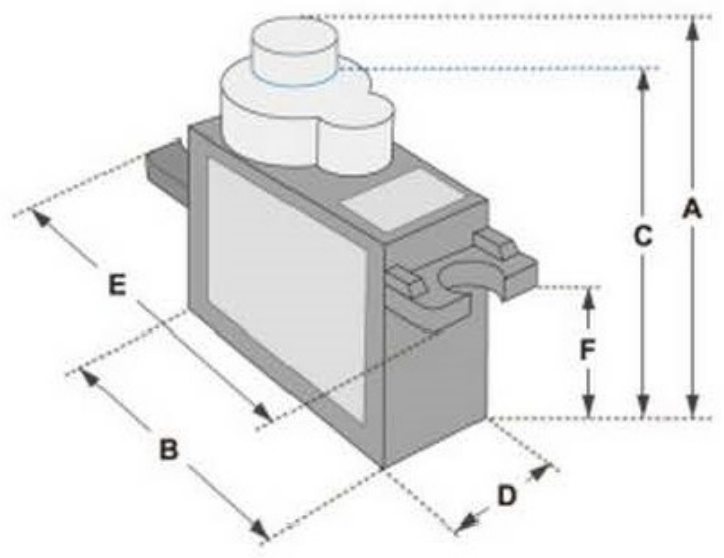

Figure 1. Servo Motor

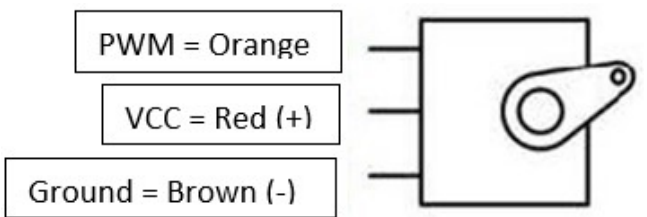

Figure 2. Arms of the Servo Motor 
Table 1. Dimensions and Specifications of the Servo Motor

\begin{tabular}{c}
\hline Dimensions \& Specifications \\
\hline $\mathrm{A}(\mathrm{mm}): 32$ \\
\hline $\mathrm{B}(\mathrm{mm}): 23$ \\
\hline $\mathrm{C}(\mathrm{mm}): 28.5$ \\
\hline $\mathrm{D}(\mathrm{mm}): 12$ \\
\hline $\mathrm{E}(\mathrm{mm}): 32$ \\
\hline $\mathrm{F}(\mathrm{mm}): 19.5$ \\
\hline Speed $(\mathrm{sec}): 0.1$ \\
\hline Torque $(\mathrm{kg}-\mathrm{cm}): 2.5$ \\
\hline Weight $(\mathrm{g}): 14.7$ \\
\hline Voltage $: 4.8-6$
\end{tabular}

\subsection{Arduino Board}

The Arduino is a programmable electronic platform which allows users to easily create prototypes. Along with a breadboard and other pieces of circuitry equipment, the Arduino can be used to make various electronic input, output, and sensory systems [9]. Aside from basic electronic hardware, a wide range of complex devices, including sensors, are made to be compatible with the Arduino system. The Arduino programming language is $\mathrm{C}$ based, and can be used to create a wide variety of programs. The Arduino is also made more accessible by its low cost. Most of the Arduino Uno Board cost less than 20 Malaysian Ringgit.

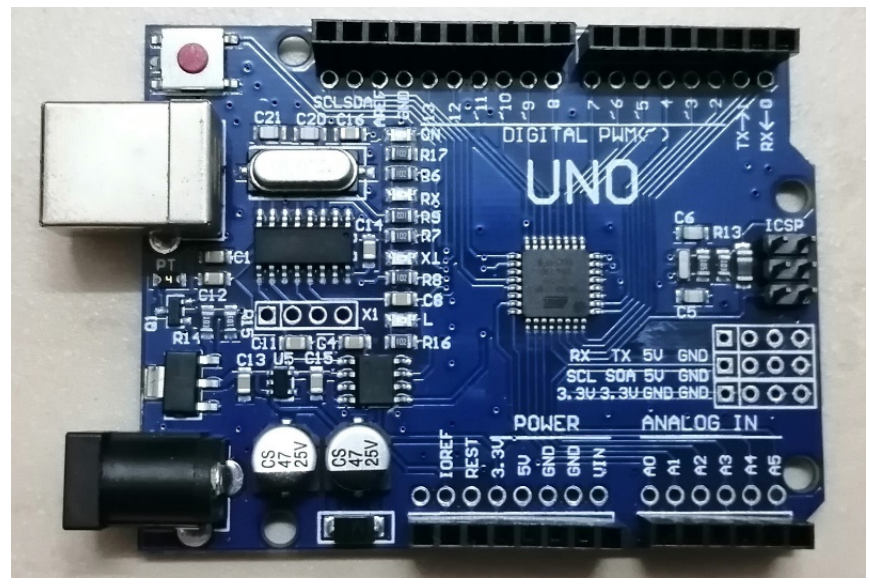

Figure 3. Arduino Board

The Arduino allows for input and output by plugging wires into 'pins.' Input pins read data (such as information from a sensor), and are capable of taking in a continuous range of values. Thus, through sensors, the Arduino can be continuously updated with information about the environment around it. The output pins send a current to any device connected to them, such as a motor or a light bulb. Unlike the input pins, there are only two possibilities for the voltage: $5 \mathrm{~V}$ or $0 \mathrm{~V}$. Gradually changing the speed of the motor requires a continuous change in voltage, which is not possible with the output pins. However, the Arduino does allow for (and has special output pins dedicated to) pulse width modulation (abbreviated as PWM). Instead of ranging over many voltages, the voltage rapidly changes from $0 \mathrm{~V}$ to $5 \mathrm{~V}$. Essentially, PWM simulates a gradual change from one voltage to another, allowing for anything connected to the pin to also vary along a continuum. For example, if $5 \mathrm{~V}$ are being outputted one fifth of the time, this is known as a $20 \%$ duty cycle, and the simulated voltage is one fifth of $5 \mathrm{~V}$, i.e. $1 \mathrm{~V}$ 


\subsection{Light Dependence Resistor}

Light Dependence Resistor (LDR) sensor module is used to detect the intensity of light [11]. It is associated with analog output pin labelled as AO respectively on the board. When there is light, the resistance of LDR will become low according to the intensity of light. The greater the intensity of light, the lower the resistance of LDR.

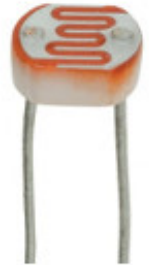

(a)

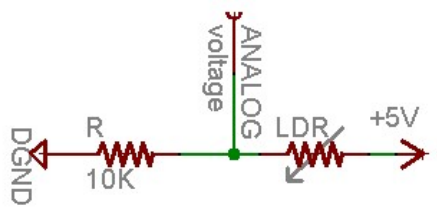

(b)

Figure 4. LDR

(a) LDR

(b) Diagram for a LDR

Table 2. LDR Specifiaction

\begin{tabular}{cccccc}
\hline Ambient Light & $\begin{array}{c}\text { Ambient } \\
\text { Light (lux) }\end{array}$ & $\begin{array}{c}\text { Photocell } \\
\text { Resistance } \\
(\boldsymbol{\Omega})\end{array}$ & $\begin{array}{c}\text { LDR }+ \\
\text { Resistor ( } \boldsymbol{\Omega})\end{array}$ & $\begin{array}{c}\text { Current thru } \\
\text { LDR+Resistor } \\
(\boldsymbol{\Omega})\end{array}$ & $\begin{array}{c}\text { Voltage } \\
\text { across } \\
\text { Resistor }\end{array}$ \\
\hline Moonlit night & $1 \mathrm{lux}$ & $70 \mathrm{~K} \Omega$ & $71 \mathrm{~K} \Omega$ & $0.07 \mathrm{~mA}$ & $0.1 \mathrm{~V}$ \\
\hline Dark room & $10 \mathrm{lux}$ & $10 \mathrm{~K} \Omega$ & $11 \mathrm{~K} \Omega$ & $0.45 \mathrm{~mA}$ & $0.5 \mathrm{~V}$ \\
\hline $\begin{array}{c}\text { Dark overcast } \\
\text { day / Bright } \\
\text { room }\end{array}$ & $100 \mathrm{lux}$ & $1.5 \mathrm{~K} \Omega$ & $2.5 \mathrm{~K} \Omega$ & $2 \mathrm{~mA}$ & $2.0 \mathrm{~V}$ \\
\hline Overcast day & 1000 lux & $300 \Omega$ & & & $3.8 \mathrm{~V}$ \\
\hline Full daylight & 10,000 lux & $100 \Omega$ & $1.1 \mathrm{~K} \Omega$ & $4.5 \mathrm{~mA}$ & $4.5 \mathrm{~V}$ \\
\hline
\end{tabular}

Table 2 shows the approximate analog voltage based on the sensor light/resistance w/a $5 \mathrm{~V}$ supply and $1 \mathrm{~K}$ pulldown resistor.

\subsection{Solar Panel}

Photovoltaic solar panels absorb sunlight as a source of energy to generate electricity. Photovoltaic modules constitute the photovoltaic array of a photovoltaic system that Generates and supplies solar electricity in Commercial and residential applications [12].

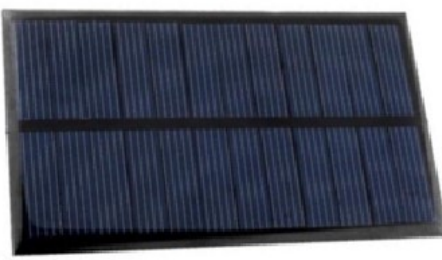

(a)

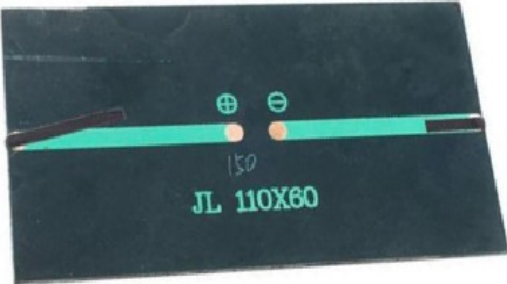

(b)

Figure 4. Solar

(a) Front Side

(b) Back Side 
Technical specifications:

1. Output voltage: $6 \mathrm{~V}$

2. Output power: $1 \mathrm{~W}$

3. Output current: $0-200 \mathrm{~mA}$

4. Dimensions: $110 \times 60 \times 2.5 \mathrm{~mm}$

\subsection{NodeMcu ESP8266}

NodeMCU is an open-source firmware and development kit that helps to prototype or build IoT product. It includes firmware which runs on the ESP8266 Wi-Fi SoC from Espressif Systems, and hardware which is based on the ESP-12 module. The firmware uses the Lua scripting language. It is based on the eLua project, and built on the Espressif Non-OS SDK for ESP8266.

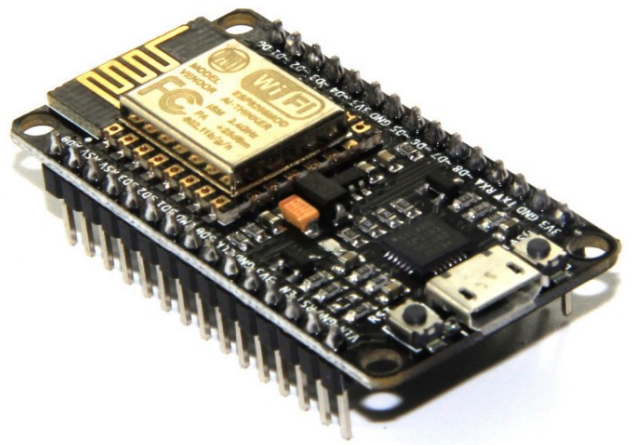

Figure 6. NodeMcu ESP8266

MCU stands for MicroController Unit - which really means it is a computer on a single chip. A microcontroller contains one or more CPUs (processor cores) along with memory and programmable input/output peripherals. They are used to automate automobile engine control, implantable medical devices, remote controls, office machines, appliances, power tools, toys and others.

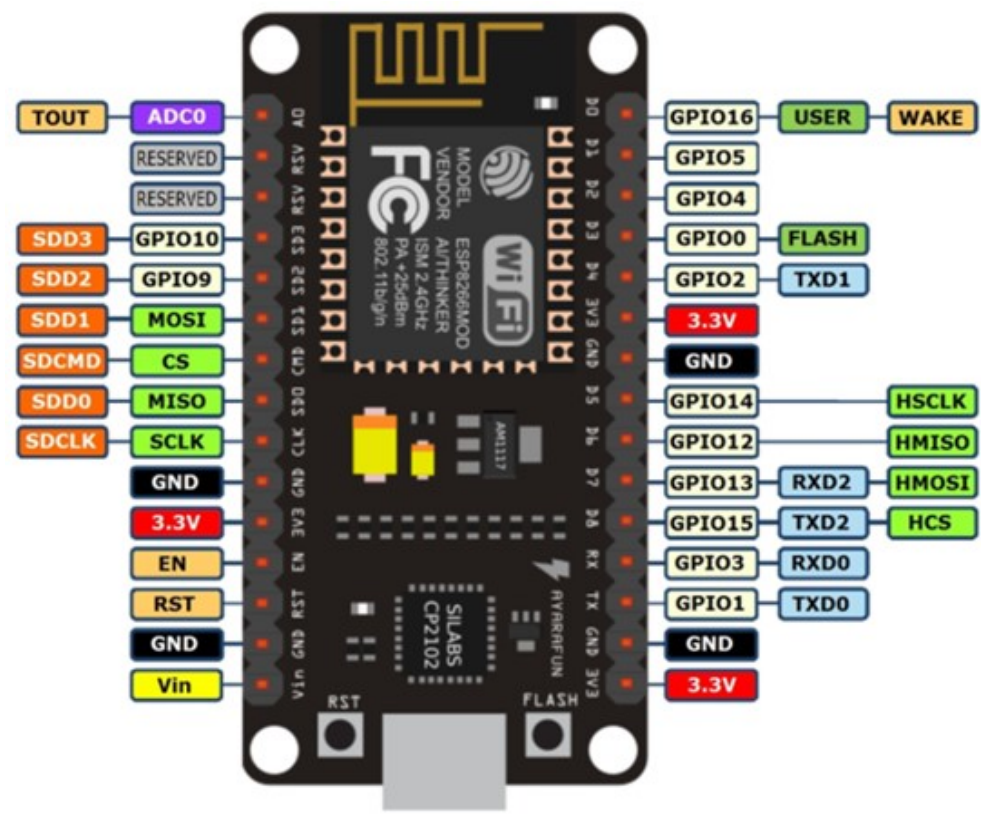

Figure 7. Pin Definition 


\section{Testing}

The first testing was the component testing and it was consist of:

1. Servo Motor Testing

This test will ensure the movement of the servo motor and the functionality. The reason why the test was conducted because when I test it for the first time, the servo motor was not function at all.

2. LDR Sensor Testing

This test is to ensure that the LDR Sensor work as it should be and the sensor can detect light. The reason why the test was conducted because LDR sensor is sensitive and easily to become malfunction.

3. Connect NodeMcu to WiFi

This test is to ensure the "NodeMcu" can connect to the wifi and to the "Blynk" app without any problem. The way to test it is by try and error on coding that will upload on "NodeMcu"

The final phase testing were:

1. Test the Solar Tracker using flashlight

This test will ensure the LDR sensor will detect the light and will follow the light. This test also will ensure that the servo motor work as it should be.

2. Manual Control Testing

This test is to ensure that the solar tracker can be control from a far (in a wifi range) by using "Blynk" apps.

3. Current Sensor Testing

This test is to ensure the current sensor can read the current flow and the data can be display on the serial monitor in "Arduino IDE"

\section{Conclusion}

Based on analysis and result of the research that have been done, it showed that most respondent really satisfied with this project because it really help to reduce the carbon footprint. It also can become as an alternative energy because solar energy is a renewable energy. In line with the expanding of technology, IoT really gave benefit to human beings.

Some strengths that can be observed in this project:

1. The solar tracker can follow artificial light

2. It can be control manually

3. Can increase the efficiency of the solar panel

The weakness, such as:

1. The LDR sensor is too sensitive easy to become malfunction

2. The servo motor will keep running even when there is no light

3. The manual control is limited by the wifi range

\section{References}

[1] Arduino, Language Reference, 2018. [Online]. Available: https://www.arduino.cc/ reference/en/. [Accessed: February 19, 2019].

[2] Components 101, 2018. [Online]. Available: https://components101.com. [Accessed: February 19, 2019].

[3] Sadeque, F, Design and Implementation of Automated Solar Tracking System. 2014. doi: 10.13140/RG.2.2.21509.65765. [Online]. Available: https://www.researchgate.net/publication/ 3260 16216_Design_and_Implementation_of_Automated_Solar_Tracking_System. [Accessed: February 19, 2019].

[4] T. Tudorache, and L. Kreindler, "Design of a Solar Tracker System for PV Power Plants," IoT, vol. 7, no. 1, 2010.

[5] Servo Motor. (n.d.). "Retrieved from Imperial College London, Department of Electrical and Electronic Engineering website", 2019. [Online]. Available: http://www.ee.ic.ac.uk/pcheung/ teaching/de1_ee/stores/sg90_datasheet.pdf. [Accessed: February 19, 2019]. 
[6] LDR Sensor. (n.d.). "Retrieved from cactus.io website", [On-line]. Available: http://cactus.io/hookups/sensors/light/ ldr/hookup-arduino-to-ldr-sensor. [Accessed: February 17, 2019].

[7] ESP8266 NodeMCU. (n.d.). CITYOSAIR website, 2018. [Online]. Available: https://cityosair.readme.io/docs/esp8266-nodemcu. [Accessed: February 19, 2019].

[8] Acrobotic, "ESP8266 Programming Using Arduino IDE (Mac OSX andWindows)," 2016. [Online]. Available: https://www.youtube.com/watch?v=G6CqvhXpBKM. [Accessed: February 19, 2019].

[9] A. Sanjeev, "Interface an LCD screen with an Arduino to provide a display for your project." 2018. [Online]. Available: https://maker.pro/arduino/tutorial/how-to-connect-an-lcd-displayto-your-arduino. [Accessed: February 17, 2019].

[10] Blynk.io, "Getting Started with Blynk," 2019. [Online]. Available: https://blynk.io/en/gettingstarted. [Accessed: February 19, 2019].

[11] TatvaSoft, "Top 12 Sofware Development Methodologies \& its Advantages/ Diadvantages." 2015. [Online]. Available: https://www.tatvasoft.com/blog/top-12-software-developmentmethodologies-and-its-advantages-disadvantages/. [Accessed: February 17, 2019].

[12] E. Õnapuu, "Internet of Thing Solution," IoT Design Methodology, 2016. [Online]. Available: http://johanna.ld.ttu.ee/idu0080/wp-content/uploads/2016/02/Loeng10Lecture_IoTDesign Methodology.pdf. [Accessed: February 17, 2019]. 